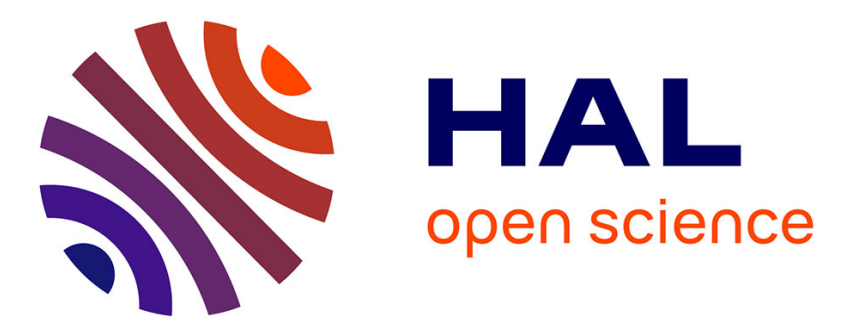

\title{
Heteroleptic copper(I)-polypyridine complexes as efficient sensitizers for dye sensitized solar cells
}

Martina Sandroni, Favereau Ludovic, Aurélien Planchat, Huriye Akdas-Kilig, Nadine Szuwarski, Yann Pellegrin, Errol Blart, Hubert Le Bozec, Mohammed Boujtita, Fabrice Odobel

\section{To cite this version:}

Martina Sandroni, Favereau Ludovic, Aurélien Planchat, Huriye Akdas-Kilig, Nadine Szuwarski, et al.. Heteroleptic copper(I)-polypyridine complexes as efficient sensitizers for dye sensitized solar cells. Journal of Materials Chemistry A, 2014, 2 (26), pp.9944-9947. 10.1039/c4ta01755b . hal-01092135

\section{HAL Id: hal-01092135 \\ https://hal.science/hal-01092135}

Submitted on 14 Nov 2018

HAL is a multi-disciplinary open access archive for the deposit and dissemination of scientific research documents, whether they are published or not. The documents may come from teaching and research institutions in France or abroad, or from public or private research centers.
L'archive ouverte pluridisciplinaire $\mathbf{H A L}$, est destinée au dépôt et à la diffusion de documents scientifiques de niveau recherche, publiés ou non, émanant des établissements d'enseignement et de recherche français ou étrangers, des laboratoires publics ou privés. 


\title{
Heteroleptic copper(I)-polypyridine complexes as efficient sensitizers for dye sensitized solar cells
}

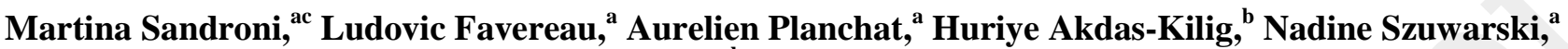 \\ Yann Pellegrin, ${ }^{a}$ Errol Blart, ${ }^{a}$ Hubert Le Bozec, ${ }^{b}$ Mohammed Boujtita ${ }^{\mathrm{a}}$ and Fabrice Odobel ${ }^{a}$
}

The synthesis and the physico-chemical characterizations of HETPHEN based heteroleptic copper(I)-bis(diimine) complexes are reported. In $\mathrm{TiO}_{2}$ based dye sensitized solar 10 cells (DSCs), the latter display impressive photoconversion efficiencies (PCEs), unprecedented for first row transition metal coordination complexes.

Since $1991^{1}$ and the discovery of DSC (Grätzel cells), many attempts to replace the costly and toxic (albeit remarkably efficient) ruthenium15 polypyridine complexes have been reported. ${ }^{2,3}$ Copper(I)-bis(diimine) complexes have early shown promising results in this field. ${ }^{4,5} 6$ Lately, the use of heteroleptic copper(I) complexes has afforded significant PCEs thanks to an improved extinction coefficient in the visible and electron transfer vectorialization. ${ }^{6}$ The latter point is an essential criterion to fulfil 20 in the design of efficient sensitizers for $\mathrm{TiO}_{2}$. Indeed, each ligand is set to play one (or more) well-defined role such as anchoring, passivation of the surface and assisting charge injection. Accordingly, ligands differ by their molecular structures and therefore by their electronic natures. In the course of our program on heteroleptic bis-diimine copper(I) complexes, ${ }^{7}$,

${ }_{25}{ }^{8,9}$ prepared according to the HETPHEN concept developed by Schmittel and colleagues, ${ }^{10}$ we have prepared and studied four new stable heteroleptic copper(I) complexes $\left[\mathrm{CuL}^{0} \mathrm{~L}^{\mathrm{n}}\right]^{+}$hereafter named $\mathbf{C n}(\mathrm{n}=1-4$, Figure 1).

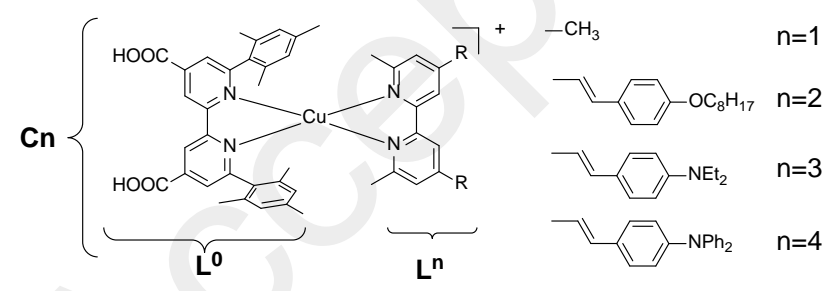

Figure 1. Molecular structures of $\mathbf{L}^{\mathbf{n}}$ and $\mathbf{C n}(\mathrm{n}=1-4)$

30

The anchoring ligand $\mathbf{L}^{\mathbf{0}}$ (6,6'-dimesityl-2,2'-bipyridine-4,4'dicarboxylic acid) is based on the classical 4,4'-dicarboxylic acid bipyridine onto which were attached two mesityl groups in positions 6 and 6', providing the necessary steric bulk to avoid the formation of

35 homoleptic complexes. The ligands completing the coordination sphere of the copper(I) ion belong to the family of 4,4'-bis(styrylphenyl)-2,2'bipyridines, derivatized with electron releasing moieties of different strength. Methyl groups in $\alpha$ of the chelating nitrogen atoms confer rigidity to the final scaffold, preserving the excited state from exciplex 40 quenching and excessive flattening upon excitation, to a certain extent.
Three complexes C2, C3 and C4, bearing respectively alkoxy, N,Ndiethylamine and N,N-diphenylamine moieties were thus isolated. For the sake of comparison, a fourth model complex $\left[\mathrm{CuL}^{0} \mathrm{~L}^{1}\right]^{+}$(C1) was synthesized, with $\mathrm{L}^{1}=2,2^{\prime}, 4,4^{\prime}$-tetramethylbipyridine.

45 The syntheses of all ligands are reported in ESI. The HETPHEN modus operandi was used to isolate C1-4 and started with the synthesis of the $\left.\mathrm{Cu}\left(\mathbf{L}^{0}\right)\right]^{+}$intermediate in DMF. An equivalent of $\mathrm{L}^{\mathrm{n}}$ was subsequently added dropwise, entailing an immediate colour change of the medium from yellow to deep red. Impurities were removed by size 50 exclusion chromatography. A similar protocol was used to isolate the dimethyl-ester forms of each complex (named hereafter Cnester, $n=1-4$, synthesis given in ESI).

The electronic absorption spectra of the complexes were recorded in solution and on nanocrytalline $\mathrm{TiO}_{2}$ films (Figures 2 and S3). All the 55 complexes featured the classical MLCT absorption band at ca. $500 \mathrm{~nm}$ (Table 1 and Figure 2). ${ }^{11}$ The increased conjugation of the $\pi$ system on both $\mathbf{L}^{0}$ and $\mathbf{L}^{\mathbf{n}}(\mathrm{n}=2-4)$ induces a stabilization of the $\pi^{*}$ orbitals, explaining the red-shift of this transition compared to the benchmark bisneocuproine $\mathrm{Cu}(\mathrm{I})$ complex $\mathbf{C 5}$ (Figure S7). ${ }^{9}$ One notices that the MLCT 60 bands are more intense as well, because of the increased ground state dipolar moment generated by the combination of electron poor $\mathbf{L}^{\mathbf{0}}$ and electron rich $\mathbf{L}^{\mathbf{n}}$. The complexes $\mathbf{C 3}$ and $\mathbf{C 4}$ present higher light harvesting efficiency in the visible than $\mathbf{C} 1$ and $\mathbf{C 2}$ because of an intense additional intraligand charge transfer transition (ILCT), located at the 65 edge of the visible around $420 \mathrm{~nm}^{9}$

\begin{tabular}{lc|cc} 
& $\lambda(\mathrm{nm})\left[\varepsilon\left(\mathrm{M}^{-1} . \mathrm{cm}^{-1}\right]\right.$ & \multicolumn{2}{|c}{$\mathrm{E}(\mathrm{V})^{*}[\Delta \mathrm{E}(\mathrm{mV})]$} \\
\hline C1 & $477\left[4.7 \cdot 10^{3}\right]$ & $0.94[96]$ & - \\
C2 & $500\left[9.8 \cdot 10^{3}\right]$ & $0.91[96]$ & - \\
C3 & $504\left[1.3 \cdot 10^{4}\right]$ & $1.08^{\mathrm{a}}[-]$ & $0.80^{\mathrm{a}}[-]$ \\
C4 & $502\left[1.4 \cdot 10^{4}\right]$ & $1.03^{\mathrm{b}}[-]$ & $0.95^{\mathrm{b}}[-]$
\end{tabular}

Table 1. UV-Visible and electrochemical data for C1-4. *data collected with the methyl ester forms of C1-4.

70 This very intense ILCT transition corresponds to a shift of the electron density from the electron rich amine moieties to the electron poor pyridine. Such band does exist for $\mathbf{C} \mathbf{2}$ too, but is significantly blue-shifted compared to $\mathbf{C} \mathbf{3}$ and $\mathbf{C} \mathbf{4}$ because of the poorer electron donating power of $\mathbf{L}^{2}$. Spectra recorded on $\mathrm{TiO}_{2}$ transparent electrodes (Figure S3) feature 75 the same patterns than those recorded in solution phase (Figure 2). Overall, the complexes displayed a rather broad and intense absorption over a large wavelength frame $\left(\lambda_{\text {onset }} \sim 620 \mathrm{~nm}\right)$, revealing their potentials 
as wide band gap semi-conductors sensitizers.

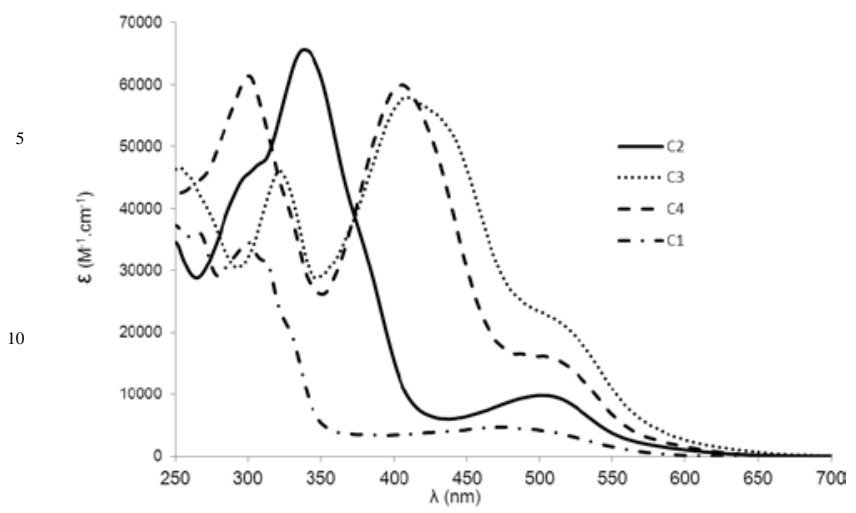

15 Figure 2. UV-Visible spectra of complexes C1 (dash-dot), C2 (plain), C3 (dot) and $\mathbf{C 4}$ (dash) recorded in dichloromethane.

No luminescence was detected upon excitation in the MLCT band, regardless the conditions. This could be due to cis-trans isomerization of 20 the vinyl double bond ${ }^{12}$ or the lesser rigidity of the Cu-bpy coordination cage compared to Cu-Phen, facilitating the deleterious exciplex quenching.

To record better resolved cyclic and pulsed voltammograms (no adsorption of the dye on the electrode), these measurements were 25 performed on the diester forms of complexes. The latter featured the expected, reversible copper-centred oxidation around $1 \mathrm{~V}$ vs. SCE (Table 1). The voltammograms of C3ester and C4ester displayed an additional oxidation wave at 0.95 and $0.80 \mathrm{~V}$ vs. SCE respectively, corresponding to the removal of one electron from the $\mathrm{NR}_{2}(\mathrm{R}=$ ethyl or phenyl) amine 30 moieties. Only differential pulse voltammetry allowed discriminating the two close oxidation steps for complex C4ester. The higher $\mathrm{Cu}^{\mathrm{II}} / \mathrm{Cu}^{\mathrm{I}}$ potentials displayed by C3ester and C4ester likely originate in the coulombic repulsion between the copper cation and the electrogenerated hole on the amine fragment.

35 The combination of electrochemical and UV-Vis data allowed evaluating the Gibbs energies associated to the various charge transfer processes. In all cases, both charge injection and dye regeneration are exergonic (ca. $300 \mathrm{meV}$, see Table S1 in SI). Energy-wise, C1-4 feature roughly the same behaviours. $\mathrm{TiO}_{2}$ electrodes were dipped while still hot 40 for two days in ethanolic solutions of C1-4 and the photovoltaic devices were then assembled with a platinum counter-electrode, sealed with a hotmelt polymer frame and their performances along those of the reference benchmark N719 were evaluated under AM 1.5 calibrated artificial sunlight (Table 2 and SI for details).

45

\begin{tabular}{ccccc} 
& Voc (mV) & Jsc $\left(\mathrm{mA.cm}{ }^{-2}\right)$ & FF (\%) & PCE (\%) \\
\hline $\mathbf{C 1}^{\mathrm{a}}$ & 475 & 2.20 & 72.80 & 0.76 \\
$\mathbf{C 2}^{\mathrm{a}}$ & 535 & 2.89 & 72.54 & 1.12 \\
$\mathbf{C 3}^{\mathrm{a}}$ & 545 & 7.51 & 71.52 & 2.93 \\
$\mathbf{C 4}^{\mathrm{a}}$ & 565 & 6.70 & 73.32 & 2.77 \\
$\mathbf{N 7 1 9}^{\mathrm{a}}$ & 635 & 16.87 & 68.69 & 7.36 \\
\hline $\mathbf{C 1}^{\mathrm{b}}$ & 525 & 3.76 & 74.64 & 1.47 \\
$\mathbf{C 2}^{\mathrm{b}}$ & 565 & 4.99 & 72.39 & 2.04 \\
$\mathbf{C 3}^{\mathrm{b}}$ & 605 & 10.86 & 70.97 & $\mathbf{4 . 6 6}$ \\
$\mathbf{C 4}^{\mathrm{b}}$ & 625 & 10.13 & 69.76 & 4.42
\end{tabular}

Table 2. Photovoltaic data for DSCs based on $\mathrm{TiO}_{2}$ sensitization by $\mathbf{C 1 - 4}$ without (a) and with (b) CDCA. Voc: open circuit voltage; Jsc: short circuit current density; $\mathrm{ff}=$ fill factor.

50 The weakest PCE is afforded by C1 based DSCs, grounded in low photocurrent and photovoltage. The latter is assigned to a lower light harvesting efficiency (LHE) and probably to an exacerbated charge recombination with the electrolyte. Indeed, the positive charge of C1-4 entails a coulombic repulsion between them on the surface of $\mathrm{TiO}_{2}$,

55 increasing the number of unoccupied adsorption sites and thus recombination centres. C3, C4 and $\mathbf{C 2}$ are a lot bulkier than $\mathbf{C 1}$, and thus passivate more the surface of the semi-conductor, yielding a higher Voc. This is further confirmed by the higher dark current displayed by C1based DSCs (see SI). Besides, both C1 and C2 yield poor photocurrents, 60 likely because of their less intense absorption coverages of the solar spectrum, leading to an overall weaker LHE (see Figures 3\& S4).

The short circuit currents of $\mathbf{C} 3$ and $\mathbf{C} 4$ based DSCs are by far the highest of the series, in part because of the presence of ILCT bands in the visible domain, increasing the LHE. This is confirmed by the incident 65 photon to current efficiency (IPCE) recorded on each DSC, where a current generation is indeed monitored between 400 and $460 \mathrm{~nm}$ for C3 and C4 (around $43 \%$ at $410 \mathrm{~nm}$ ). C1 and C2 based DSCs, being deprived of such ILCT above $400 \mathrm{~nm}$ consequently display lesser LHE and IPCE.

Spin coating a $0.1 \mathrm{M}$ CDCA (chenodeoxycholic acid) ethanolic 70 solution onto the photo-electrodes prior to the final sealing is anticipated to eliminate the deleterious self-quenching process induced by aggregation. Rewardingly, unprecedented improvements in the power conversion efficiencies (PCEs) of all DSCs were observed upon such CDCA-surface treatment. First of all, an increase of the photopotential 75 was observed for all DSCs. C1-4 based devices exhibited a 50-60 mV rise of the Voc, together with a decrease of the dark current. This improvement was therefore assigned to the higher electron concentration in the $\mathrm{CB}$ and to a passivation of recombination sites by the co-adsorbent molecules. In the case of $\mathbf{C 2}$, the octyl chains may provide a built-in, 80 efficient protection of titanium dioxide's surface, thus explaining the lesser increase of the Voc (ca. $30 \mathrm{mV})$. The electron lifetime $\left(\tau_{\mathrm{n}}\right)$ and mean transit time $\left(\tau_{\mathrm{tr}}\right)$ of photoinjected charge carriers were then recorded by intensity-modulated photovoltage spectroscopy (IMVS) and intensitymodulated photocurrent spectroscopy (IMPS). However, these 85 measurements reveal that no significant improvement of both $\tau_{\mathrm{n}}$ and $\tau_{\mathrm{d}}$ was observed when CDCA was added in the preparation of the series of solar cells (see SI). As a result, the charge collection efficiency $\eta_{\text {coll }}$ measured as a function of the illumination intensity is quite similar for all the dyes (see SI).

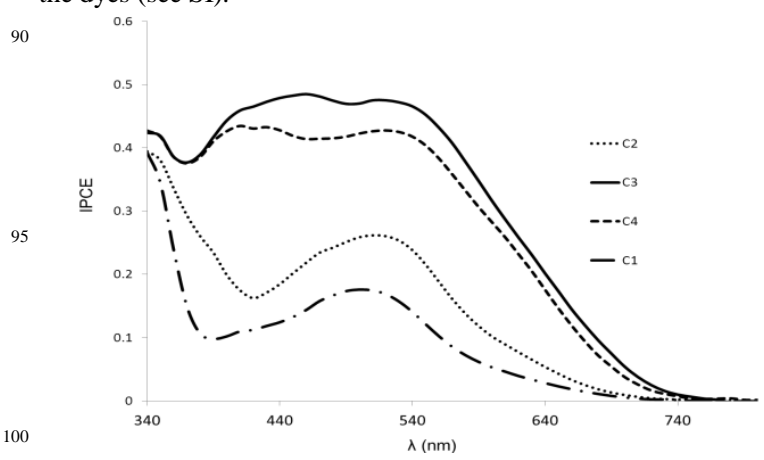

Figure 3. IPCE for DSCs sensitized with C1 (dash-dot), C2 (dot), C3 (plain), and C4 (dash) recorded with CDCA.

The most spectacular improvement of the PCE originates in the rise of 
the Jsc for all devices. One calculates a $70 \%$ increase of the photocurrent for C1 and C4 and 45 and 50\% for C2 and C3 based photovoltaic devices, respectively. For a better understanding, IPCEs of DSCs with and without CDCA treatment were compared (Figure S5). A significant

5 increase of the IPCE is observed for CDCA-treated cells, regardless the dye (Figure 3), together with a broadening of the signals. Several reasons can be invoked to rationalize this important result. First, CDCA molecules release protons and this bends the conduction band downwards, increasing thus the driving force of the electron injection into 10 the semi-conductor, and consequently improving the electron injection yield. ${ }^{13}$ Second, a noticeable increase of the absorbance of C1-4 based photo-electrodes was monitored upon CDCA treatment, along with a slightly broadened MLCT transition (Figure S4). These subtle changes in the absorption spectra of the chemisorbed complexes are in line with the 15 IPCE, and are probably grounded in a reorganization of the dye monolayer upon CDCA adsorption. The role of CDCA is often associated with the disruption of dye aggregates and certainly comes into play here, especially due to the presence of organic styryl branches on the complexes C2-4. Based on the effect of CDCA on both IPCE 20 measurements and on the Jsc enhancement, we conclude that the main role of CDCA with these complexes is certainly to decrease the aggregation on $\mathrm{TiO}_{2}$ surface leading to higher LHE and injection quantum yield. In these conditions, DSCs provided a maximum PCE of $4.66 \%$ for C3-based device. This is to date the highest PCE ever reported for a DSC 25 based on a copper(I) complex sensitizer, and hold great promises for the future of these cheap solar cells. Most highly performing dyes, including ruthenium complexes, are neutral species, while these first series of copper(I) complexes are positively charged. This is certainly one weak point of these dyes, which can be overcome by using new ancillary 30 ligands

\section{Conclusions}

We successfully isolated four stable heteroleptic copper(I)polypyridine complexes, using the HETPHEN concept. Through a careful choice of ligands, unprecedented PCE were measured, reaching $4.66 \%$. 35 The new anchoring ligand $\mathbf{L}^{\mathbf{0}}$ paves the route to prepare other sensitizers as it certainly forms stable heteroleptic copper(I) with many unhindered diimine ligands. This contribution brings further credit to these molecular complexes as efficient sensitizers for DSCs, en route for a cheap and less toxic substitute to ruthenium dyes.

40

\section{Acknowledgements}

ANR agency is gratefully acknowledged for the financial support of these researches through program HeteroCop ( ${ }^{\circ}$ ANR-09-BLAN-0183-01).

\section{Notes and references}

$45{ }^{a}$ UNAM, Université Nantes, Angers, Le Mans, CEISAM, Chimie Et Interdisciplinarité, Synthèse, Analyse, Modélisation CNRS, UMR CNRS 6230, 2, rue de la Houssinière - BP 92208; 44322 NANTES Cedex 3 (France) E-mail: Fabrice.Odobel@univ-nantes.fr and Mohammed.Boujtita@univ-nantes.fr

$50{ }^{\frac{1}{b} U M R}$ CNRS 6226-Université de Rennes 1, Sciences Chimiques de Rennes, Campus de Beaulieu, 35042 Rennes Cedex, France. . ${ }^{c}$ Current address: CEMCA UMR CNRS 6521, Université de Bretagne Occidentale, 6 avenue Victor Le Gorgeu, 29238 Brest, France

$\dagger$ Electronic Supplementary Information (ESI) available: Synthesis of the 55 complexes, absorption spectra on $\mathrm{TiO}_{2}$ and electron lifetime $\left(\tau_{n}\right)$, mean electron transit time $\left(\tau_{\text {tr }}\right)$ and $\eta_{\text {coll }}$ measured by IMVS and IMPS. See DOI: $10.1039 / \mathrm{b} 000000 \mathrm{x} /$

1. O'Regan, B.; Gratzel, M., Nature 1991, 353 (6346), 737-740.

60 2. Hagfeldt, A.; Boschloo, G.; Sun, L.; Kloo, L.; Pettersson, H., Chem. Rev. 2010, 110 (11), 6595-6663.

3. Mishra, A.; Fischer, M. K. R.; Bauerle, P., Angew. Chem., Int. Ed. 2009, 48, 2474-2499.

4. Sakaki, S.; Kuroki, T.; Hamada, T., Dalton Trans. 2002, (6), 840-842. 65 5. Bozic-Weber, B.; Constable, E. C.; Furer, S. O.; Housecroft, C. E.; Troxler, L. J.; Zampese, J. A., Chem. Commun. 2013, 49 (65), 7222-7224. 6. Bozic-Weber, B.; Constable, E. C.; Housecroft, C. E., Coord. Chem. Rev. 2013, 257 (21-22), 3089-3106.

7. Pellegrin, Y.; Sandroni, M.; Blart, E.; Planchat, A.; Evain, M.; Bera, N. 70 C.; Kayanuma, M.; Sliwa, M.; Rebarz, M.; Poizat, O.; Daniel, C.; Odobel, F., Inorg. Chem. 2011, 50 (22), 11309-11322.

8. Sandroni, M.; Kayanuma, M.; Planchat, A.; Szuwarski, N.; Blart, E.; Pellegrin, Y.; Daniel, C.; Boujtita, M.; Odobel, F., Dalton Trans. 2013, 42 (30), 10818-10827.

75 9. Sandroni, M.; Kayanuma, M.; Rebarz, M.; Huriye, A.-K.; Pellegrin, Y.; Blart, E.; Poizat, O.; Le Bozec, H.; Sliwa, M.; Daniel, C.; Odobel, F., Dalton Trans. 2013, 42, 10818-10827.

10. Schmittel, M.; Ganz, A., Chem. Commun. 1997, (11), 999-1000.

11.Armaroli, N.; Accorsi, G.; Cardinali, F.; Listorti, A., Top. Curr. Chem. 80 2007, 280 (Photochemistry and Photophysics of Coordination Compounds I), 69-115.

12. Aubert, V.; Ordronneau, L.; Escadeillas, M.; Williams, J. A. G.; Boucekkine, A.; Coulaud, E.; Dragonetti, C.; Righetto, S.; Roberto, D.; Ugo, R.; Valore, A.; Singh, A.; Zyss, J.; Ledoux-Rak, I.; Le Bozec, H.; 85 Guerchais, V., Inorg. Chem. 2011, 50 (11), 5027-5038.

13. Nazeeruddin, M. K.; Humphry-Baker, R.; Liska, P.; Grätzel, M., J. Phys. Chem. B 2003, 107 (34), 8981-8987. 
5

10

Graphical abstract for entry

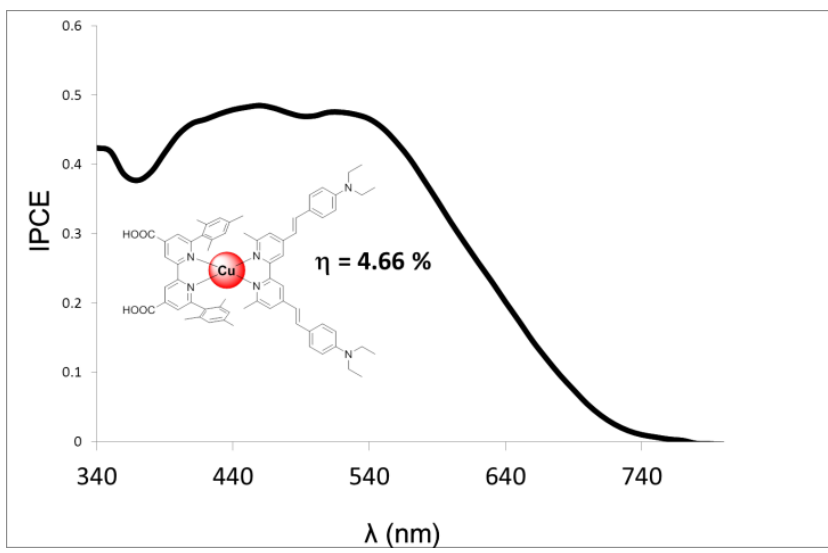

